\title{
Hubungan Faktor Risiko yang dapat Dimodifikasi dengan Kejadian Penyakit Jantung Koroner di RS Dr. M. Djamil Padang
}

Suchi IImi Herman ${ }^{1}$, Muhammad Syukri ${ }^{2}$, Efrida $^{3}$

\begin{abstract}
Abstrak
Sumatera Barat merupakan provinsi dengan prevalensi penyakit jantung tertinggi ke-4 di Indonesia. Prevalensi penyakit ini meningkat disebabkan karena faktor risiko yang dapat dimodifikasi yaitu dislipidemia, hipertensi, diabetes melitus, merokok, dan obesitas. Faktor risiko tersebut terkait dengan peningkatan kejadian PJK. Tujuan penelitian ini adalah untuk mengetahui hubungan faktor risiko yang dapat dimodifikasi dengan kejadian PJK. Penelitian ini merupakan penelitian analitik dengan desain potong lintang yang dilakukan di RS Dr. M. Djamil Padang dari Desember 2012 sampai Mei 2013. Populasi penelitian ini adalah seluruh pasien PJK yang dirawat inap dan telah dilakukan angiografi pada Januari 2012 sampai Desember 2012 dengan 68 orang sebagai subjek penelitian. Data pasien didapatkan dari rekam medik. Data dideskripsikan dengan tabel dan dianalisis dengan uji chi-square. Hasil penelitian menunjukkan distribusi frekuensi terbanyak pasien PJK terdapat pada kadar kolesterol HDL rendah (64,6\%) dan hipertensi $(72,5 \%)$, namun hasil uji bivariat tidak menunjukkan hubungan yang bermakna antara kadar kolesterol HDL rendah dan hipertensi terhadap kejadian PJK. Kesimpulan hasil penelitian ini ialah kadar kolesterol HDL rendah dan hipertensi belum tentu menyebabkan PJK.
\end{abstract}

Kata kunci: penyakit jantung koroner, faktor risiko, HDL

\begin{abstract}
West Sumatra is a province with the highest prevalence of heart disease 4th in Indonesia. The prevalence of this disease increases due to modifiable risk factors, namely dyslipidemia, hypertension, diabetes mellitus, smoking, and obesity. The risk factors associate with an increased incidence of Coronary Heart Disease (CHD). The objective of this study was to determine the relationship of modifiable risk factors with CHD events. This study was a crosssectional analytic design conducted at Hospital Dr. M. Djamil Padang from December 2012 until May 2013. The population in this study were all hospitalized CHD patients and angiography was performed in January 2012 December 2012 with 68 patients as a research subject. Obtained from the patient's medical record. The data described in tables and analyzed with the chi-squared test. The result showed that the frequency distribution of most CHD patients are at low levels of HDL cholesterol (64.6\%) and hypertension (72.5\%). Bivariate test results showed no significant association between low HDL cholesterol and hypertension on the incidence of CHD. The conclusion is the low HDL cholesterol levels and hypertension not necessarily lead to CHD.
\end{abstract}

Keywords: coronary heart disease, risk factors, HDL

Affiliasi penulis : 1. Pendidikan Dokter FK UNAND (Fakultas Kedokteran Universitas Andalas Padang), 2. Bagian Jantung dan Pembuuh Darah FK UNAND, 3. Bagian Patologi Klinik FK UNAND Korespondensi : Suchi Ilmi Herman, E-mail: suchi.iha@gmail,com,Telp : 08126798310

\section{PENDAHULUAN}

Penyakit Jantung Koroner (PJK) adalah ketidaksanggupan jantung bekerja yang dapat terjadi secara akut maupun kronik dan timbul karena kekurangan suplai darah pada miokardium sehubungan 
dengan proses penyakit pada sistem nadi koroner. Manifestasinya dapat berupa angina pektoris, infark miokard, fibrilasi ventrikular atau kematian jantung mendadak. ${ }^{1,2}$

Pada tahun 2009, Sumatera Barat merupakan provinsi dengan prevalensi penyakit jantung tertinggi ke-4 di Indonesia. ${ }^{3}$ Berdasarkan statistik World Health Organization (WHO), setiap tahunnya terdapat 16 juta kematian akibat penyakit kardiovaskular dan pada tahun 2001, 7,2 juta dari 16 juta kematian tersebut adalah akibat penyakit jantung koroner. Prediksi WHO, pada tahun 2020 akan terdapat 25 juta kematian penduduk dunia akibat penyakit kardiovaskular dan separuhnya disebabkan oleh PJK. ${ }^{4}$

Berbagai faktor yang berperan penting terhadap timbulnya PJK yang disebut sebagai faktor risiko PJK, antara lain usia, jenis kelamin dan riwayat keluarga sakit jantung sebagai faktor risiko yang tidak dapat dimodifikasi. Dislipidemia, hipertensi, diabetes melitus, merokok dan obesitas sebagai faktor risiko yang dapat dimodifikasi. Semakin banyak faktor risiko yang ada pada seseorang maka semakin besar pula kemungkinan orang itu menderita penyakit jantung koroner. $^{5}$

Penyakit jantung koroner merupakan masalah kesehatan masyarakat yang penting karena morbiditas dan mortalitasnya yang tinggi. Angka kejadian penyakit ini juga mengalami peningkatan setiap tahunnya, maka dengan mengetahui faktor risiko yang dapat dimodifikasi dan bagaimana hubungannya dengan PJK diharapkan meningkatkan kewaspadaan masyarakat dan klinisi sehingga dapat menurunkan kejadian penyakit ini. Oleh karena itu, perlu dilakukan penelitian tentang hubungan faktor risiko yang dapat dimodifikasi dengan kejadian penyakit jantung koroner di RS Dr. M. Djamil yaitu kadar kolesterol total tinggi, kadar kolesterol HDL rendah, kadar kolesterol LDL tinggi, kadar trigliserida tinggi, hipertensi dan diabetes melitus.

\section{METODE}

Penelitian ini merupakan penelitian analitik observasional dengan desain potong lintang. Penelitian ini dilakukan di Bagian Rekam Medik RS Dr. M. Djamil Padang mulai bulan Desember 2012 sampai dengan
Mei 2013. Populasi penelitian ini adalah seluruh pasien rawat inap di bagian jantung $\mathrm{RS}$ Dr. M. Djamil Padang yang telah dilakukan angiografi dan tercatat dalam rekam medik antara Januari 2012 - Desember 2012. Subjek pada penelitian ini dipilih dengan teknik simple random sampling dengan kriteria eksklusi pasien disertai diagnosis kelainan katup dan kelainan jantung bawaan sehingga didapatkan total sampel berjumlah 68 sampel sebagai subjek penelitian.

\section{HASIL}

Telah dilakukan penelitian terhadap seluruh pasien rawat inap yang dilakukan angiografi pada Januari 2012 - Desember 2012 dengan 68 pasien sebagai subjek penelitian. Data pasien didapatkan dari rekam medik.

\section{Karakteristik Subjek Penelitian}

Tabel 1. Distribusi frekuensi umur subjek penelitian

\begin{tabular}{llcc}
\hline Umur & $\mathbf{n}$ & Rerata & SD \\
\hline PJK & 43 & 55,63 & 7,850 \\
Tidak PJK & 25 & 55,76 & 9,382 \\
\hline Jumlah & 68 & & \\
\hline
\end{tabular}

Berdasarkan Tabel 1 didapatkan bahwa rerata umur penderita PJK adalah 55 tahun.

Tabel 2. Distribusi frekuensi jenis kelamin subjek penelitian

\begin{tabular}{lcccccc}
\hline \multirow{2}{*}{ Jenis } & \multicolumn{2}{c}{ PJK } & \multicolumn{2}{c}{ Tanpa PJK } & \multicolumn{2}{c}{ Total } \\
\cline { 2 - 7 } Kelamin & $\mathbf{n}$ & $\%$ & $\mathbf{n}$ & $\%$ & $\mathbf{n}$ & $\%$ \\
\hline Perempuan & 5 & 22,7 & 17 & 77,3 & 22 & 100 \\
Laki - laki & 38 & 82,6 & 8 & 17,4 & 46 & 100 \\
\hline Jumlah & 43 & 63,2 & 25 & 36,8 & 68 & 100 \\
\hline
\end{tabular}

Menurut Tabel 2, laki - laki menderita PJK terbanyak yaitu $82,6 \%$ sedangkan perempuan $22,7 \%$.

Berdasarkan tabel 3 dapat dilihat distribusi frekuensi faktor risiko PJK terbanyak terdapat pada kadar HDL rendah dan hipertensi. Kadar HDL rendah ditemukan pada 95\% sampel, 64,6\% mengalami PJK dan 35,4\% tidak mengalami PJK. Sedangkan hipertensi ditemukan pada $60 \%$ sampel, $72,5 \%$ menyatakan PJK, 27,5\% tidak mengalami PJK. 


\section{Analisis Univariat}

Tabel 3. Distribusi frekuensi faktor risiko PJK berdasarkan variabel yang diuji

\begin{tabular}{|c|c|c|c|c|c|c|}
\hline \multirow[t]{2}{*}{ Variabel } & \multicolumn{2}{|c|}{ PJK } & \multicolumn{2}{|c|}{$\begin{array}{c}\text { Tanpa } \\
\text { PJK }\end{array}$} & \multicolumn{2}{|c|}{ Total } \\
\hline & $n$ & $\%$ & $\mathbf{n}$ & $\%$ & $\mathbf{n}$ & $\%$ \\
\hline \multicolumn{7}{|c|}{ Kadar Kolesterol } \\
\hline \multicolumn{7}{|l|}{ Total } \\
\hline Normal & 20 & 57,1 & 15 & 42,9 & 35 & 100 \\
\hline Tinggi & 23 & 69,7 & 10 & 30,3 & 33 & 100 \\
\hline Jumlah & 43 & 63,2 & 25 & 36,8 & 68 & 100 \\
\hline \multicolumn{7}{|c|}{ Kadar Kolesterol } \\
\hline \multicolumn{7}{|l|}{ HDL } \\
\hline Normal & 1 & 33,3 & 2 & 66,7 & 3 & 100 \\
\hline Rendah & 42 & 64,6 & 23 & 35,4 & 65 & 100 \\
\hline Jumlah & 43 & 63,2 & 25 & 36,8 & 68 & 100 \\
\hline \multicolumn{7}{|c|}{ Kadar Kolesterol } \\
\hline \multicolumn{7}{|l|}{ LDL } \\
\hline Normal & 20 & 55,6 & 16 & 44,4 & 36 & 100 \\
\hline Tinggi & 23 & 71,9 & 9 & 28,1 & 32 & 100 \\
\hline Jumlah & 43 & 63,2 & 25 & 36,8 & 68 & 100 \\
\hline \multicolumn{7}{|c|}{ Kadar Trigliserida } \\
\hline Normal & 32 & 60,4 & 21 & 39,6 & 53 & 100 \\
\hline Tinggi & 11 & 73,3 & 4 & 26,7 & 15 & 100 \\
\hline Jumlah & 43 & 63,2 & 25 & 36,8 & 68 & 100 \\
\hline \multicolumn{7}{|l|}{ Hipertensi } \\
\hline Ada & 29 & 72,5 & 11 & 27,5 & 40 & 100 \\
\hline Tidak & 14 & 50,0 & 14 & 50,0 & 28 & 100 \\
\hline Jumlah & 43 & 63,2 & 25 & 36,8 & 68 & 100 \\
\hline \multicolumn{7}{|c|}{ Diabetes Melitus } \\
\hline Ada & 8 & 61,5 & 5 & 38,5 & 13 & 100 \\
\hline Tidak & 35 & 63,6 & 20 & 36,4 & 55 & 100 \\
\hline Jumlah & 43 & 63,2 & 25 & 36,8 & 68 & 100 \\
\hline
\end{tabular}

\section{Analisis Bivariat}

Hubungan faktor risiko yang dapat dimodifikasi dengan kejadian PJK di RS Dr. M. Djamil dianalisis menggunakan analisis bivariat dengan uji korelasi chisquare.

Tabel 4. Hubungan faktor risiko kadar kolesterol total terhadap kejadian PJK

\begin{tabular}{lccccccc}
\hline Kadar & \multicolumn{2}{c}{ PJK } & \multicolumn{2}{c}{ Tanpa PJK } & \multicolumn{2}{c}{ Total } & p \\
\cline { 2 - 6 } $\begin{array}{l}\text { Kolesterol } \\
\text { Total }\end{array}$ & $\mathbf{n}$ & $\%$ & $\mathbf{n}$ & $\%$ & $\mathbf{N}$ & $\%$ & \\
\hline Normal & 20 & 57,1 & 15 & 42,9 & 35 & 100 & 0,41 \\
Tinggi & 23 & 69,7 & 10 & 30,3 & 10 & 100 & \\
\hline Jumlah & 43 & 63,2 & 25 & 36,8 & 68 & 100 & \\
\hline
\end{tabular}

Pada hasil penelitian ini dapat dilihat bahwa persentase kadar kolesterol total tinggi pada pasien PJK adalah $69,7 \%$, namun nilai $p>0,05$, yang artinya tidak ada hubungan yang bermakna antara kadar kolesterol total dengan kejadian PJK.

Tabel 5. Hubungan faktor risiko kadar kolesterol HDL terhadap kejadian PJK

\begin{tabular}{llcccccc}
\hline $\begin{array}{l}\text { Kadar } \\
\text { Kolesterol }\end{array}$ & \multicolumn{2}{c}{ PJK } & \multicolumn{2}{c}{ Tanpa PJK } & \multicolumn{2}{c}{ Total } & p \\
\cline { 2 - 6 } \begin{tabular}{l} 
HDL \\
\cline { 3 - 6 }
\end{tabular} & $\mathbf{n}$ & $\%$ & $\mathbf{n}$ & $\%$ & $\mathbf{n}$ & $\%$ & \\
\hline Normal & 1 & 33,3 & 2 & 66,7 & 3 & 100 & 0,55 \\
Rendah & 42 & 64,6 & 23 & 35,4 & 65 & 100 & \\
Jumlah & 43 & 63,2 & 25 & 36,8 & 68 & 100 & \\
\hline
\end{tabular}

Pada Tabel 5 terlihat nilai $p>0,05$ yang artinya tidak terdapat hubungan yang signifikan antara kadar kolesterol HDL dengan kejadian PJK walaupun pada distribusi frekuensi menunjukkan pasien PJK terbanyak adalah dengan kadar kolesterol HDL rendah.

Tabel 6. Hubungan faktor risiko kadar kolesterol LDL terhadap kejadian PJK

\begin{tabular}{lccccccc}
\hline \multirow{2}{*}{$\begin{array}{l}\text { Kadar } \\
\text { Kolesterol }\end{array}$} & \multicolumn{2}{c}{ PJK } & \multicolumn{2}{c}{ Tanpa PJK } & \multicolumn{2}{c}{ Total } & p \\
\cline { 2 - 6 } LDL & $\mathbf{n}$ & $\%$ & $\mathbf{n}$ & $\%$ & $\mathbf{n}$ & $\%$ & \\
\hline Normal & 20 & 55,6 & 16 & 44,4 & 36 & 100 & 0,254 \\
Tinggi & 23 & 71,9 & 9 & 28,1 & 32 & 100 & \\
\hline Jumlah & 43 & 63,2 & 25 & 36,8 & 68 & 100 & \\
\hline
\end{tabular}

Pada Tabel 6 dapat dilihat bahwa nilai $p>0,05$ yang artinya tidak ada hubungan yang signifikan antara kadar kolesterol LDL dengan kejadian PJK, namun persentase kadar LDL tinggi pada pasien PJK cukup tinggi, yaitu $71,9 \%$.

Tabel 7. Hubungan faktor risiko kadar trigliserida terhadap kejadian PJK

\begin{tabular}{lccccccc}
\hline Kadar & \multicolumn{2}{c}{ PJK } & \multicolumn{2}{c}{ Tanpa PJK } & \multicolumn{2}{c}{ Total } & p \\
\cline { 2 - 6 } Trigli- & $\mathbf{n}$ & $\%$ & $\mathbf{n}$ & $\%$ & $\mathbf{n}$ & $\%$ & \\
serida & & & & & & & \\
\hline Normal & 32 & 60,4 & 21 & 39,6 & 53 & 100 & 0,538 \\
Tinggi & 11 & 73,3 & 4 & 26,7 & 15 & 100 & \\
Jumlah & 43 & 63,2 & 25 & 36,8 & 68 & 100 & \\
\hline
\end{tabular}

Pada Tabel 7 diatas dapat dilihat bahwa persentase kadar trigliserida tinggi pada pasien PJK 
adalah $73,3 \%$, namun nilai $p>0,05$ yang artinya tidak ada hubungan yang signifikan antara kadar trigliserida dengan kejadian PJK.

Tabel 8. Hubungan faktor risiko hipertensi terhadap kejadian PJK

\begin{tabular}{|c|c|c|c|c|c|c|c|}
\hline \multirow[t]{2}{*}{ Hipertensi } & \multicolumn{2}{|c|}{ PJK } & \multicolumn{2}{|c|}{$\begin{array}{c}\text { Tanpa } \\
\text { PJK }\end{array}$} & \multicolumn{2}{|c|}{ Total } & \multirow[t]{2}{*}{$p$} \\
\hline & $\mathbf{n}$ & $\%$ & $n$ & $\%$ & $\mathbf{N}$ & $\%$ & \\
\hline Ada & 29 & 72,5 & 11 & 27,5 & 40 & 100 & 0,101 \\
\hline Tidak & 14 & 50,0 & 14 & 50,0 & 28 & 100 & \\
\hline Jumlah & 43 & 63,2 & 25 & 36,8 & 68 & 100 & \\
\hline
\end{tabular}

Pada hasil uji chi-square diatas dapat dilihat bahwa didapatkan nilai $p>0,05$ yang artinya tidak terdapat hubungan yang signifikan antara hipertensi dengan kejadian walaupun pada distribusi frekuensi menunjukkan terdapat pasien PJK terbanyak dengan hipertensi (72,5\%).

Tabel 9. Hubungan faktor risiko diabetes melitus terhadap kejadian PJK

\begin{tabular}{lrrrrrrr}
\hline \multirow{2}{*}{$\begin{array}{l}\text { Miabetes } \\
\text { Melitus }\end{array}$} & \multicolumn{2}{c}{ PJK } & \multicolumn{2}{c}{ Tanpa PJK } & Total & $\mathbf{p}$ \\
\cline { 2 - 6 } & $\mathbf{n}$ & $\%$ & $\mathbf{n}$ & $\%$ & $\mathbf{n}$ & $\%$ & \\
\hline Ada & 8 & 61,5 & 5 & 38,5 & 13 & 100 & 1,0 \\
Tidak & 35 & 63,6 & 20 & 36,4 & 55 & 100 & \\
Jumlah & 43 & 63,2 & 25 & 36,8 & 68 & 100 & \\
\hline
\end{tabular}

Pada hasil pengolahan data diatas dapat dilihat bahwa didapatkan nilai $p>0,05$ artinya tidak terdapat hubungan yang signifikan antara diabetes melitus dengan kejadian PJK.

\section{Analisis Multivariat}

Data yang dianalis secara multivariat harus memenuhi nilai $p<0,25$. Didapatkan satu variabel yang memenuhi syarat tersebut yaitu hipertensi $(p=0,101)$, sedangkan untuk melakukan analisis multivariat harus terdapat lebih dari dua variabel yang akan diuji. Sehingga analisis multivariat tidak dapat dilakukan.

\section{PEMBAHASAN}

\section{Faktor Risiko PJK}

Penyakit jantung koroner bukanlah penyakit yang terjadi dengan sendirinya. Banyak hal yang dapat mempengaruhi kejadian PJK. Pada penelitian
Framingham, Multiple Risk Factors Interventions Trial dan Minister Heart Study (PROCAM), diketahui bahwa faktor risiko seseorang untuk menderita PJK ditentukan melalui interaksi dua atau lebih faktor risiko antara lain faktor risiko yang tidak dapat dimodifikasi seperti keturunan, umur, jenis kelamin dan faktor risiko yang dapat dimodifikasi seperti dislipidemia, hipetensi, merokok, DM, stres, dan obesitas. ${ }^{6}$

Berdasarkan penelitian ini yang dilakukan di RS Dr. M. Djamil Padang periode Januari 2012 Desember 2012, didapatkan hasil dari 33 responden dengan kadar kolesterol tinggi, 69,7\% (23 orang) mengalami PJK. Sebanyak 65 responden dengan kadar kolesterol HDL rendah, 64,6\% (42 orang) mengalami PJK. Distribusi kadar kolesterol LDL tinggi adalah $71,9 \%$. Satu dari dua responden dengan kadar trigliserida tinggi mengalami PJK (50\%). Sebanyak $72,5 \%$ (29 orang) pasien dengan hipertensi mengalami PJK, dan 8 dari 13 responden dengan DM (61,5\%) mengalami PJK.

Penelitian Yanti pada tahun 2008, didapatkan bahwa kadar kolesterol HDL memiliki hubungan terhadap kejadian PJK. ${ }^{7}$ Berdasarkan penelitian Diana di Semarang dengan judul Analisis Faktor Risiko Kejadian Penyakit Jantung Koroner di RSUP Dr. Kariadi Semarang, dari 128 sampel yang ada, yang memiliki kolesterol total tinggi 59 (46,10\%) pasien, kadar trigliserida tinggi 37 (28,90\%) pasien, hipertensi 89 (69,5\%) pasien, diabetes melitus 82 (64,10\%) pasien. ${ }^{8}$ Menurut Fajri, dari 346 responden didapatkan hasil faktor risiko yang terbukti berpengaruh adalah kolesterol total $(p=0,027)$, LDL $(p=0,010)$, dan hipertensi $(p=0,009) .{ }^{9}$ Diantara kadar kolesterol total, kadar kolesterol HDL, kadar kolesterol LDL, kadar trigliserida, hipertensi, dan diabetes melitus dapat dilihat distribusi frekuensi terbanyak terdapat pada kadar HDL rendah dan hipertensi. Kadar HDL rendah terjadi pada 95\% sampel, 64,6\% mengalami PJK dan $35,4 \%$ tidak mengalami PJK. Hipertensi terjadi pada $60 \%$ sampel, $72,5 \%$ menunjukkan terjadinya PJK, 27,5\% tidak mengalami PJK. Perbedaan hasil penelitian ini dengan beberapa penelitian lain mungkin disebabkan karena perbedaan desain penelitian, pada penelitian ini desain yang digunakan adalah potong lintang sedangkan penelitian lain banyak menggunakan desain studi kasus. 


\section{Pengaruh Kadar Kolesterol Total Terhadap PJK}

Peningkatan kadar kolesterol total berhubungan kuat dengan risiko PJK. Kadar kolesterol total $>200 \mathrm{mg} / \mathrm{dL}$ meningkatkan risiko PJK. ${ }^{10}$ Hasil analisis bivariat dengan uji chi-square didapatkan bahwa nilai $p=0,526$ yang artinya tidak ada hubungan yang signifikan antara kadar kolesterol total dengan kejadian PJK. Sesuai dengan penelitian Sulistyo tahun 2012 membuktikan bahwa tidak ada hubungan yang bermakna antara kadar kolesterol total dengan kejadian PJK. ${ }^{11}$ Penelitian yang dilakukan oleh Fajri pada tahun 2011, dari hasil analisis bivariat dengan uji kai-kuadrat, didapatkan hasil bahwa terdapat hubungan kadar kolesterol total terhadap kejadian PJK dengan nilai $p=$ 0,027 . $^{9}$ Hasil penelitian Diana pada tahun 2012 juga menunjukkan bahwa terdapat hubungan kadar kolesterol total terhadap kejadian PJK setelah dianalisis secara bivariat dan multivariat. ${ }^{8}$ Perbedaan hasil penelitian ini dengan beberapa penelitian lain mungkin disebabkan karena perbedaan metode penelitian, pada penelitian ini desain yang digunakan adalah potong lintang sedangkan penelitian lain banyak menggunakan desain studi kasus.

\section{Pengaruh Kadar Kolesterol HDL Terhadap PJK}

Kolesterol HDL mengangkut kolesterol daripembuluh darah kembali ke hati untuk dibuang sehingga mencegah penebalan dinding pembuluh darah atau mencegah terjadinya proses aterosklerosis. Jadi, makin rendah kadar kolesterol HDL makin besar kemungkinan terjadinya PJK. ${ }^{10,12}$ Dari hasil analisis bivariat dengan uji chi-square didapatkan nilai $p=0,550$ yang artinya tidak terdapat hubungan yang signifikan antara kadar kolesterol HDL dengan kejadian PJK. Penelitian oleh Sulistyo tahun 2012 juga membuktikan bahwa tidak ada hubungan yang bermakna antara kadar kolesterol HDL dengan kejadian PJK. ${ }^{11}$ Begitu juga dengan Mamat tahun 2008 membuktikan bahwa tidak terdapat hubungan yang bermakna antara kenaikan kadar HDL dalam darah dengan kejadian PJK $(p=0,489){ }^{6} \quad$ Perbedaan beberapa penelitian lain dengan penelitian ini mungkin disebabkan karena perbedaan desain penelitian, pada penelitian ini desain yang digunakan adalah potong lintang sedangkan penelitian lain banyak menggunakan desain studi kasus.

\section{Pengaruh Kadar Kolesterol LDL Terhadap PJK}

Kadar kolesterol LDL yang tinggi akan menyebabkan penebalan dinding pembuluh darah. ${ }^{10}$ Berdasarkan hasil penelitian didapatkan kadar kolesterol LDL tinggi $73,3 \%$ dari 15 orang responden mengalami PJK. Hasil analisis bivariat dengan uji chisquare didapatkan bahwa nilai $p=0,374$ yang artinya tidak ada hubungan yang signifikan antara kadar kolesterol LDL dengan kejadian PJK. Sesuai dengan penelitian Sulistyo tahun 2012 yang membuktikan bahwa tidak ada hubungan yang bermakna antara kadar kolesterol LDL dengan kejadian PJK. ${ }^{11}$ Berdasarkan penelitian Fajri tahun 2011 di Surakarta, didapatkan hubungan kadar kolesterol LDL dengan kejadian PJK. ${ }^{9}$ Perbedaan dengan penelitian tersebut mungkin disebabkan karena perbedaan metode penelitian, pada penelitian ini desain yang digunakan adalah potong lintang sedangkan penelitian lain banyak menggunakan desain studi kasus.

\section{Pengaruh Kadar Trigliserida terhadap PJK}

Kadar trigliserida yang tinggi merupakan faktor risiko untuk terjadinya PJK. ${ }^{6}$ Hasil penelitian yang dilakukan analisis bivariat dengan uji chi-square didapatkan nilai $\mathrm{p}=0,5$ yang artinya tidak ada hubungan yang signifikan antara kadar trigliserida dengan kejadian PJK. Penelitian Julio tahun 2011 juga tidak menemukan hubungan yang bermakna antara kadar trigliserida dengan kejadian PJK $(p=0,772){ }^{13}$ Penelitian Diana pada tahun 2012 membuktikan bahwa terdapat hubungan antara kadar trigliserida dengan kejadian PJK $(p=0,019){ }^{8}$ Penelitian yang dilakukan oleh Sulistyo pada tahun 2012 juga menunjukkan bahwa terdapat hubungan antara kadar trigliserida terhadap PJK berdasarkan nilai $p$ yang didapat sebesar 0,022 dan OR $3,7 .^{11}$ Perbedaan hasil pada penelitian ini mungkin disebabkan karena perbedaan dalam klasifikasi variabel penelitian, pada penelitian ini desain yang digunakan adalah potong lintang sedangkan penelitian lain banyak menggunakan desain studi kasus.

\section{Pengaruh Hipertensi Terhadap PJK}

Peningkatan tekanan darah sistemik akibat hipertensi meningkatkan resistensi terhadap pemompaan darah dari ventrikel kiri, sehingga beban 
kerja jantung bertambah. ${ }^{6}$ Hasil uji chi-square didapatkan nilai $p=0,101$ yang artinya tidak terdapat hubungan yang signifikan antara hipertensi dengan kejadian PJK, namun dari hasil yang didapatkan secara kuantitatif, dari keseluruhan sampel dengan hipertensi, sebanyak 72,5\% mengalami PJK. Sesuai dengan hasil penelitian Sulistyo pada tahun 2012 didapatkan nilai $\mathrm{p}=0,057$ yang membuktikan tidak terdapat hubungan hipertensi terhadap kejadian PJK. ${ }^{11}$ Begitu juga dengan penelitian Julio tahun 2011 yang tidak menemukan hubungan yang bermakna antara hipertensi dengan kejadian PJK $(p=0,097){ }^{13}$ Berbeda dengan hasil penelitian Fajri pada tahun 2011 didapatkan nilai $p=0,009$ yang membuktikan terdapat hubungan antara hipertensi terhadap kejadian PJK. ${ }^{9}$ Penelitian oleh Singh tahun 2010 juga menunjukkan hubungan antara hipertensi dengan kejadian PJK $(p=0,0001) .{ }^{14}$ Perbedaan hasil dengan penelitian lain mungkin disebabkan karena perbedaan metode penelitian, pada penelitian ini desain yang digunakan adalah potong lintang sedangkan penelitian lain banyak menggunakan desain studi kasus.

\section{Pengaruh Diabetes Melitus terhadap PJK}

Diabetes melitus berhubungan dengan perubahan fisik-patologi pada sistem kardiovaskular. Diantaranya dapat berupa gangguan pembuluh darah dan disfungsi endotel yang pada akhirnya akan meningkatkan risiko terjadinya $\mathrm{PJK} .{ }^{6}$ Hasil penelitian ini mendapatkan 8 dari 13 responden dengan DM (61,5\%) mengalami PJK dan nilai $\mathrm{p}$ yang didapat dari hasil analisis bivariat uji chi-square sebesar 1,0 yang artinya tidak terdapat hubungan yang signifikan antara diabetes melitus dengan kejadian PJK. Sesuai dengan penelitian Isabelle et al pada tahun 2006 didapatkan tidak ada hubungan yang bermakna antara DM dengan kejadian PJK $(p=0,161) .{ }^{15}$

Penelitian Sulistyo pada tahun 2012 membuktikan bahwa terdapat hubungan yang signifikan antara DM dengan kejadian PJK. ${ }^{11}$ Begitu juga dengan penelititan kasus kontrol oleh Mamat pada tahun 2008 didapatkan proporsi responden dengan gula darah puasa $>126 \mathrm{mg} / \mathrm{dL}$ pada kelompok kasus sebesar $47,5 \%$ dan pada kelompok kontrol sebesar $51,3 \%$, hasil analisis bivariat menunjukkan bahwa terdapat hubungan yang signifikan antara kadar gula darah puasa dengan kejadian PJK $(p=0,0001){ }^{6}$ Perbedaan hasil pada penelitian ini dengan penelitian lain mungkin disebabkan karena perbedaan metode penelitian, pada penelitian ini desain yang digunakan adalah potong lintang sedangkan penelitian lain banyak menggunakan desain studi kasus.

\section{KESIMPULAN}

Kadar kolesterol total, kadar kolesterol HDL, kadar kolesterol LDL, kadar trigliserida, hipertensi dan diabetes melitus tidak berhubungan dengan terjadinya PJK.

\section{UCAPAN TERIMA KASIH}

Penulis mengucapkan terima kasih kepada dr.Muhammad Syukri, SpJP dan dr. Efrida, SpPK, M.Kes, sebagai pembimbing atas masukan dan bimbingan dalam menyelesaikan skripsi ini. Kepada koresponden dan staff RS. Dr. M. Djamil Padang sebagai tempat penelitian atas fasilitas yang telah diberikan.

\section{DAFTAR PUSTAKA}

1. World Health Organization (WHO). Trends in coronary risk factor in The WHO Monica project. Int J Epidemiol 2001.1:S35-40.

2. Dorland W. Newman A. "Iskemik Miokard". Kamus Kedokteran Dorland. Edisi ke- 29. Jakarta: EGC; 2002.

3. Delima, Laurentia M, Hadi S. Prevalensi dan Faktor Determinan Penyakit Jantung di Indonesia. Buletin Penelitian Kesehatan. 2009. 37(3):142-59.

4. Gotto. Observational epidemiology and risk factor in manual of lipid disorders. Edition ke-3. Philadelphia: Lippincott Williams \& Wilkins; 2003.

5. Onny W. Pengobatan jantung koroner. 2012 ( diunduh 26 Januari 2013). Tersedia dari: URL: HYPERLINK http://www.rumahsakitmitrakemayo ran.com/

6. Mamat S. Faktor-faktor risiko yang berpengaruh terhadap kejadian penyakit jantung koroner pada kelompok usia <45 tahun (tesis). Semarang: Universitas Diponegoro; 2008.

7. Yanti. Faktor-faktor risiko kejadian penyakit jantung koroner pada penderita diabetes melitus tipe 2 (tesis). Semarang: Universitas Diponegoro; 2008. 
8. Diana Z. Analisis faktor risiko kejadian penyakit jantung koroner di RSUP Dr Kariadi Semarang (skripsi). Semarang: Universitas Muhamadiyah Semarang; 2012.

9. Fajri A. Hubungan faktor risiko dengan kejadian penyakit jantung koroner pada karyawan PT. Pupuk Kalimantan Timur (tesis). Surakarta: Universitas Muhammadiyah Surakarta; 2011.

10. Wenger NK. HT and CVD prevention: From myth to reality. Am Soc for Repro Med,2003. 1: 10 -3.

11. Sulistyo A, Ririn N. Faktor risiko kejadian PJK pada kelompok muda (tesis). Surabaya: Universitas Muhamadiyah Ponogoro; 2012.

12. American Heart Association (AHA). Cholesterol. 2006. (diunduh 24 April 2013). Tersedia dari: URL:
HYPERLINK http://www.americanheart.org

13. Julio $Y T$, Rogerio BR, Solange DA, Soane MS, Jose AF, Antonio PM. BNP and admission glucose as in-hospital mortality predictors in NON-ST elevation myocardial infarction. Cardiovascular Diabetology. 2012; 11; 47.

14. Singh A. Hubungan hipertensi sebagai faktor risiko kejadian penyakit jantung koroner di rumah sakit umum pusat Haji Adam Malik Medan (skripsi). Medan: Universitas Sumatra Utara; 2010.

15. Isabelle LH, Mariane Z, Laurent M. Relation of hyperglycemia to ST-Segment resolution after reperfusion for acute myocardial infarction (from observatoire des infarctus de Cote-d'Or survey [RICO]. Am J Cardiol. 2006; 98:167-71. 